\title{
DYNAMIC PERFORMANCE OF EXHAUST STACK MOUNTING BRACKET OF MINING EQUIPMENT
}

\author{
Nandeesh $\mathbf{M ~ N}^{1}$, Shivaprakash $\mathbf{S}^{2}$ \\ ${ }^{1} P G$ student, Mechanical Engineering, NHCE, Bangalore, Karnataka, India \\ ${ }^{2}$ Senior Assistant Professor, Mechanical Engineering, NHCE, Bangalore, Karnataka, India
}

\begin{abstract}
Engine exhaust stack mounting plays a vital role in reducing noise, vibration and ruggedness caused due to excitation and thus providing efficient role in enhancing vehicle performance and durability. Fatigue of exhaust bracket has been endlessly a concern which may susceptible to structural failure if the follow-on stress or strain are excessive than allowable. Hence vibration should be dissolute by installing a bracket for structural integrity. Engine assembly is subjected to vibration which is described by the harmonics of the engine operating frequency known as orders of the engine. In the present study, the exhaust stack mounting bracket is designed by considering the appropriate thickness, stiffeness and space provided to install the bracket. A novel design has been performed to withstand the stable vibration loads due to engine excitation. Modal frequency response analysis is performed on exhaust stack assembly to observe the stable vibration behavior of engine exhaust mounting components. In the current study, six direction of excitation is applied with respect to different orders of engine. Here the excitation refers to acceleration with respect to time domain and with the help of Fast Fourier transformation (FFT) the time domain is converted to frequency domain.
\end{abstract}

The vibration loads are subjected to very high cycle and low amplitude loading. Frequencies are obtained with low idle rpm, high idle rpm and rated rpm and with the help of interference diagram critical frequency is determined. Frequency and mode shape is obtained for axial and fore-aft direction. Stresses were evaluated at different excitation frequency and these stresses were compared with maximum allowable alternating stress limit or endurance limit of material used in this study. The fatigue factor of parent material is evaluated and found to be within the permissible limit. MSC Nastran is found to be useful tool for solving dynamic analysis and interpret the results.

Keywords: Exhaust Bracket, Dynamics, Engine Excitation and Modal Analysis

\section{INTRODUCTION}

As a conventional procedure, the track test data are extracted to ensure the proper structural design of mining equipment and to determine the life estimation. As a new trend at the initial phase of the design of the vehicle computer simulation is accounted, in order to increase the structural behavior and to predict the failure location and optimize the design wherever it's necessary and to decrease the time to market the product. Fuel consumption can be minimized by decreasing the mass of the vehicle this in turn related more and leaner structures and increased in efficient material such as aluminum and high strength steel. These materials have low damping and vibration transmissions also considering increased demands on comfort.

The improvement of engine bracket system has been the subject of intense interest for many years [2]. It is necessary to design proper engine bracket for a vehicle. As such, engine bracket has been designed as a framework to support engine. Vibrations and fatigue of engine bracket has been continuously a concern which may lead to structural failure if the resulting vibrations and stresses are severe and excessive. Prolonged exposure to whole-body vibration in the working environment may lead to fatigue and in some cases it damages the vehicle. Automotive engine mounting system must satisfy the primary tasks such as engine movement, engine rigid body dynamic behavior, and vibration isolation. Limits over the development of the mounting systems due to drivability and NVH concerns, provides savings in design resources. The main role of engine mounting system as one of the principle vehicle vibration isolating systems, besides suspension system, is to reduce the noise and vibration perceived by driver and to improve the ride comfort. $\mathrm{NVH}$ is an important vehicles characteristic motivating to achieve overall customer satisfaction. Engine is mostly mounted to the front sub frame and once installed in a vehicle, engine mounting has a significant task in decisive the vehicle vibration characteristics [1]. Resonant vibration is from unbalanced masses exist within the engine body, this is causing the designers to direct their attention to the event of top quality engine mounting brackets so as to confirm that there is improvement in riding comfort. The demand for higher playacting engine mount brackets should not be offset by arise within the production prices and/or development cycle time [3].

The fatigue failure can occur even if the structure is loaded with a low-amplitude cyclic loads when the load is applied for a longer period of time. Each cycle represents a certain amount of fatigue damage that is being accumulated by the 
structure; when the accumulated fatigue damage at the given point on the structure reaches a certain value (usually defined as unity), the fatigue failure occurs. Stress cycles that lead to the fatigue failure are a result of external loads of the structure (e.g. mechanical, temperature, vibrational load). The type of fatigue failure due to the vibrational load of the structure is known as vibrational fatigue and has been a subject of several research studies in recent years. Vibrational fatigue can be studied for harmonic or random vibration loads. In both cases the stress load leading to the fatigue failure occurs due to the structure's own dynamic response to the dynamic base-excitation, whenever vibrational fatigue occurs it is always accompanied with changes in the natural frequency and damping loss factor. This phenomenon can be utilized to predict the fatigue failure. However, when obtaining the fatigue parameters by applying harmonic vibration load, the changes in natural frequency and damping as a result of the increased local nonlinearities, lead to the varying amplitude of the stress load cycles and consequentially to the incorrect identification of the fatigue parameters. When the fatigue parameters are known one can predict the fatigue life of the structure exposed to a random-signal vibrational load using the power spectral density of the structure's stress response [5].

\section{MODAL DESCRIPTION}

Engine is considered as a rigid body all the connections are made through engine. Exhaust stack comprise of Muffler, Heat shield, Compressor, water pump, turbo charger, exhaust pipe and bracket. Based on the stiffeness, thickness and space availability bracket is designed and installed between heat shield and engine. Bracket is attached directly to engine through connection elements. This study is concentrated on bracket. This study is concentrated on bracket. Fig 1 shows the modal description and mounting bracket is shown in Fig 2.

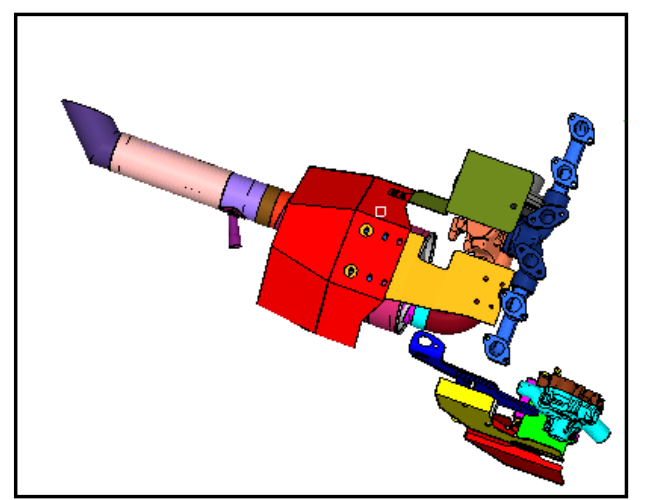

Fig -1: View of Exhaust stack mounting system

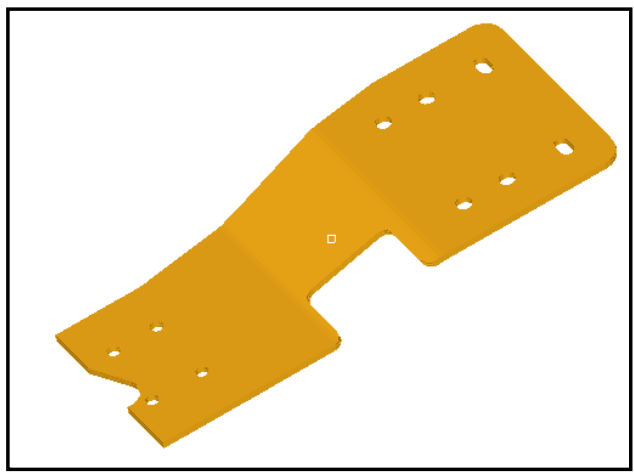

Fig -2: View of Exhaust mounting bracket

\section{METHODOLOGY}

Initially, Gravity analysis is performed to show the necessity of the bracket in exhaust mounting system. Without bracket, the deformation and stresses are high in adjacent components of exhaust stack system. To reduce the deformation and stress, bracket is introduced between engine and heat shield. This bracket will provide the path for load transfer and absorb some sort of vibrational loads which produce by engine and thus displacement and stresses are within acceptable limit. Therefore, installation of bracket will reduce the vibrational fatigue failure and bracket can experience the dynamic load for infinite number cycles. To generate the vibration loads, engine should be excited and here excitation is given in terms of acceleration. Engine acceleration data for time domain is captured in bottom front, rear and top front and rear. Axial and lateral directions were also captured to ensure the response in all the possible directions. The obtained time domain data is converted in to frequency domain to perform frequency response analysis by fast Fourier transformation [6]. With respect to damping, constant damping is applied in all modes.

Engine assembly is subjected to vibration which is characterized by the harmonics of the engine operating frequency known as the orders of the engine [1]. Excitations were applied with respect to the different orders of the engine. Modal analysis is performed and with help of an interference diagram critical frequency is determined. To show the displacement and stress induced in the structure frequency response analysis is performed. Displacement is measured in terms of micro strain. As requirements, the component should withstand infinite number of cycles and stress range and strain should not exceed the allowable limits for parent material and welded location. Results are shown for weld location and parent material and finally fatigue factor for critical location is calculated for support bracket. The detail analysis is explained in below sections.

\section{FINITE ELEMENT MODELING}

The significance of the meshing in the whole development of analysis is very vital from the point of result implementation. By size and shape of the meshing accurate results can be obtained. In terms of the mesh's uniqueness, where it was possible, hexahedral elements were used to build the mesh, while in certain regions the complexity of 
the geometry made insufficient the use of this element shape, being opted the use of tetrahedral shapes. As the bracket is having definite shape and thin structure, Shell elements are used for meshing. Fig 3 shows the meshing model.

\section{Material Properties}

Steel material is used for bracket which can withstand more dynamic loads.

Young's modulus $-2.0 \mathrm{E}+5 \mathrm{~N} / \mathrm{mm}^{2}$

Poisson's ratio -0.30

Density $-7.8 \mathrm{e}-09$ ton $/ \mathrm{mm}^{2}$

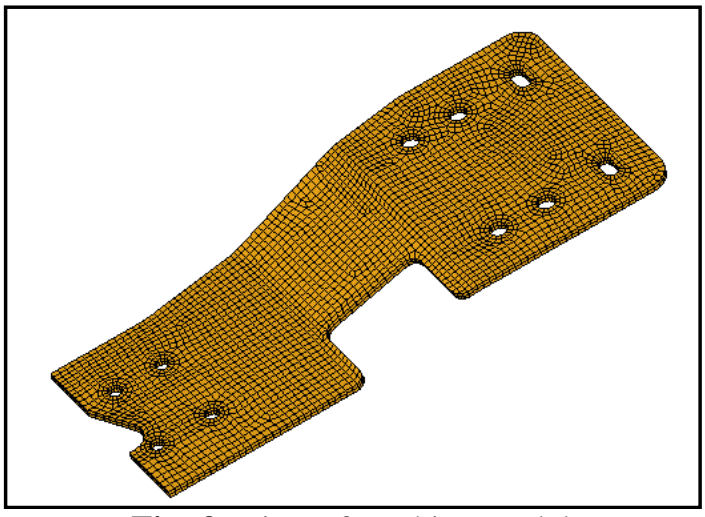

Fig -3: View of meshing model

Elements details are shown in Table 1.

Table -1: Element Details in mounting stack

\begin{tabular}{|l|l|}
\hline Number of shell elements & 3133 \\
\hline Number of RBE2 elements & 10 \\
\hline Element thickness & $6 \mathrm{~mm}$ \\
\hline
\end{tabular}

Fig. 4 shows the engine attachments to the mounting stack through RBE2 elements. Upper side of the bracket is attached to heat shield with 4 RBE2 elements and 4 RBE2 elements to engine which generates vibrational loads.

Small cut-out is provided at the mid section. Purpose of the cut-out is for wire installations.

The assembly stack consists of manifold, heat shield, compressor, turbo, muffler and exhaust pipes. As shown in Fig 4 all the attachments apart from the bracket were also modelled with RBE2 elements.

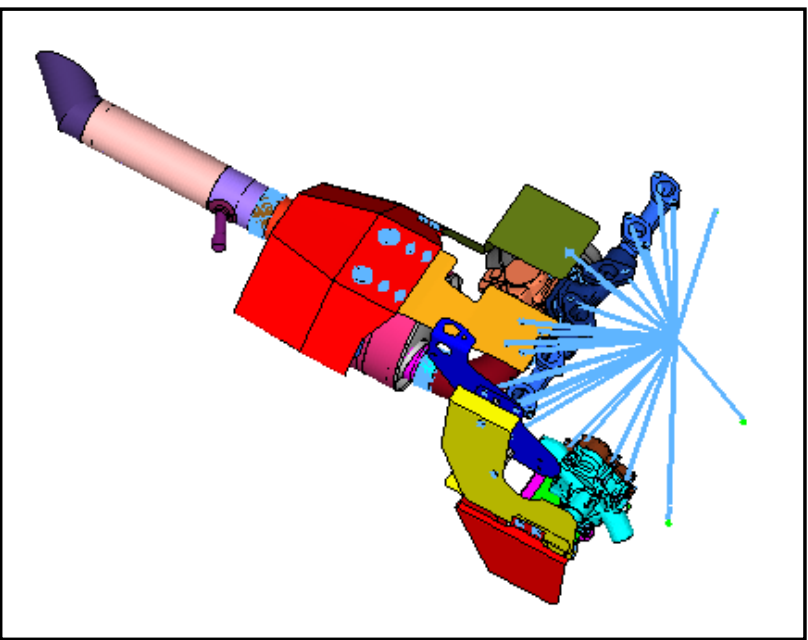

Fig -4: Connection elements from Engine

\section{Boundary Condition}

Three excitation points as shown in Fig 5. An appropriate study has been performed to identify the excitation points by considering the fore aft direction, axial direction of both top and bottom side. More number of points leads to complexity in data processing.

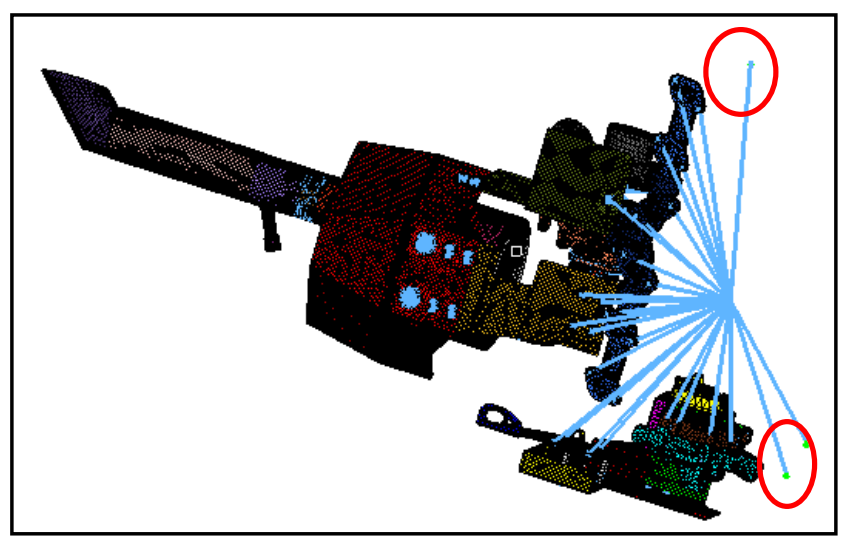

Fig -5: Exhaust stack meshed model with excitation points

\section{FFT of Engine Acceleration Data}

Engine acceleration data is extracted for frequency domain in all the directions, Bottom front left $\mathrm{X}, \mathrm{Y}$ and $\mathrm{Z}$ direction. Top rear right $\mathrm{X}$ and $\mathrm{Z}$ direction and Bottom front right $\mathrm{Y}$ direction. Some of the inputs are shown in below graphs.

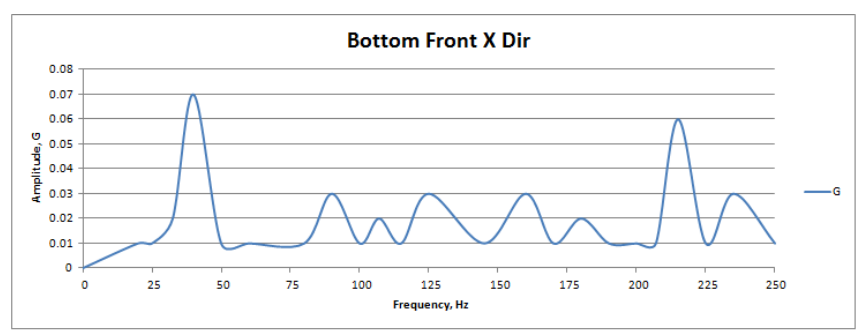

Fig -6: Engine Acceleration data for bottom front Xdirection 


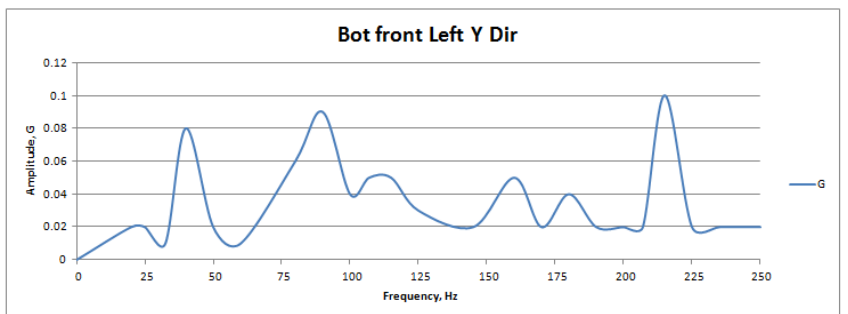

Fig -7: Engine Acceleration data for bottom front left Ydirection

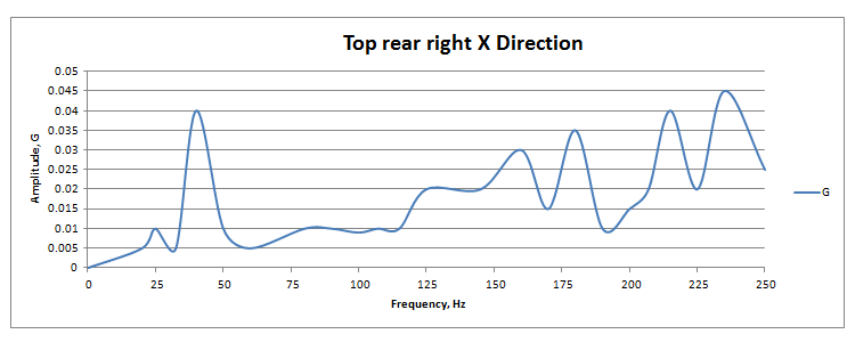

Fig -8: Engine Acceleration data for top rear right Xdirection

\section{MODAL ANALYSIS}

Modal analysis resolves the vibration uniqueness of a structure or a particular component in the form of natural frequencies and mode shapes. From this analysis we can perform detailed dynamic analysis such as transient dynamic analysis, harmonic analysis or spectrum analysis. The natural frequencies and mode shapes are important in the design of a structure for dynamic loading conditions. The operating frequency range is $0 \mathrm{~Hz}-250 \mathrm{~Hz}$.

As study is concentrated on bracket, frequency and modes shapes are extracted only on adjacent to the bracket components as shown in Table 2.

Table -2: Modes of Vibration

\begin{tabular}{|c|c|c|}
\hline MODE & FREQUENCY & MODE SHAPE \\
\hline 1 & 27.51 & Muffler \& HS (S-S First bending) \\
\hline 2 & 46.86 & Muffler \& HS (F-A First bending) \\
\hline 3 & 101.81 & $\begin{array}{l}\text { Muffler \& HS (Combination of F-A } \\
\& \text { S-S) }\end{array}$ \\
\hline 4 & 136.00 & Muffler \& HS ( S-S 2nd Bending) \\
\hline 5 & 196.00 & $\begin{array}{l}\text { Muffler \& HS (Combination of F-A } \\
\& \text { S-S) }\end{array}$ \\
\hline
\end{tabular}

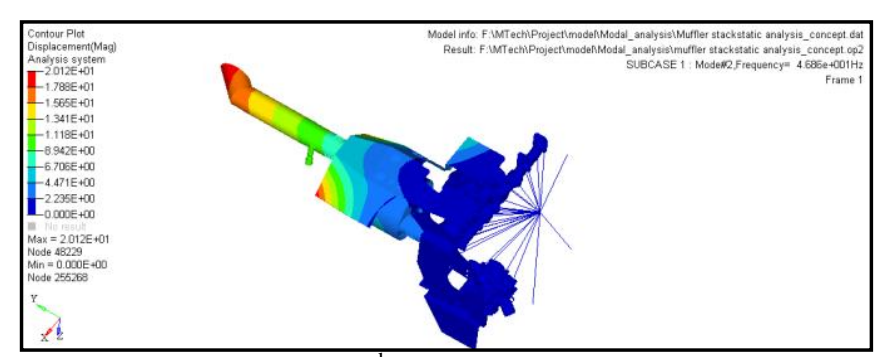

Fig -9: $2^{\text {nd }}$ Mode of vibration

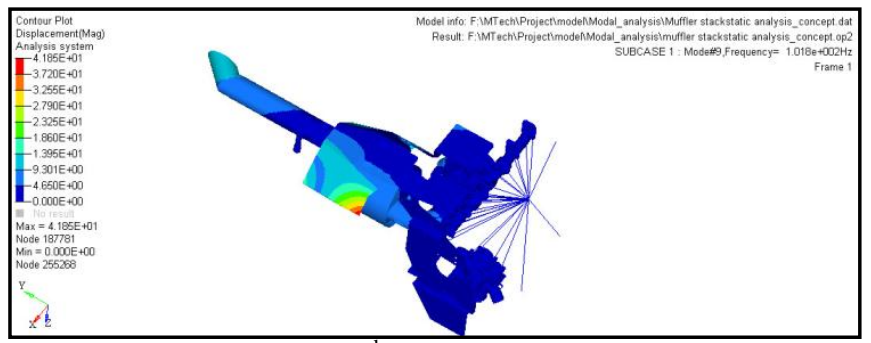

Fig -10: $3^{\text {rd }}$ Mode of vibration

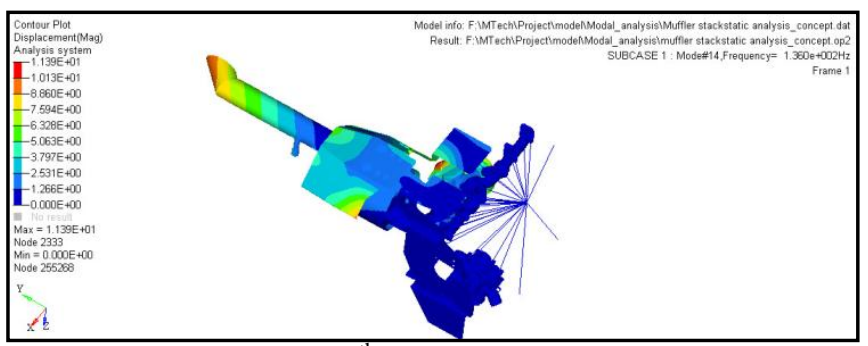

Fig -11: $4^{\text {th }}$ Mode of vibration

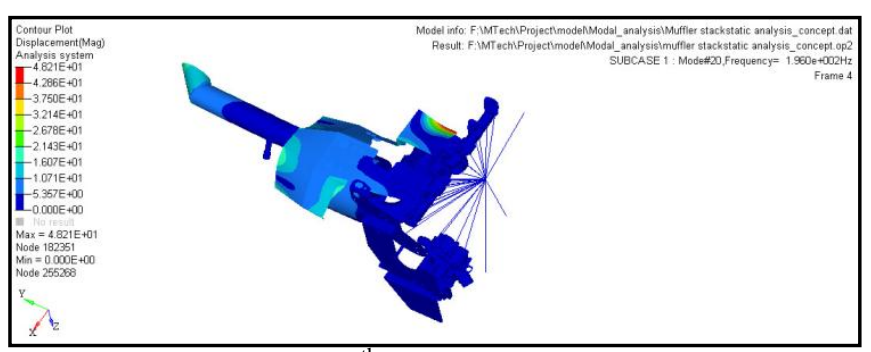

Fig -12: $5^{\text {th }}$ Mode of vibration

\section{Interference Diagram or Campbell Diagram}

A Campbell diagram plot represents a system's response spectrum as a function of its oscillation regime. The Campbell diagram represents the frequency versus the rotation speed of the shaft. The evolution of the natural frequencies corresponding to a mode is drawn in function of the rotation speed of the shaft.

A necessary condition for an Engine Order (EO) excitation to excite a stack is that the EO frequency coincides with the natural frequency of the structure. Thus to detect the possible resonant points, it remains to superpose on the graph the Engine Order lines. At the intersection between the nth Engine Order line and the line of natural frequencies of a mode characterized by $\mathrm{n}$ nodal diameters, a possible resonant condition can be found.

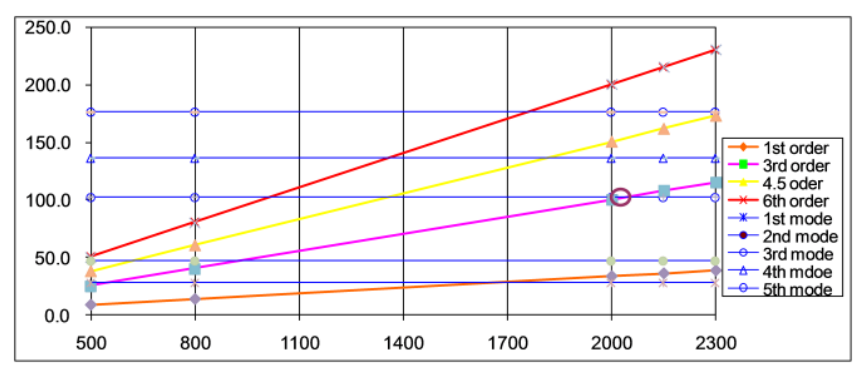

Fig -13: Resonance point identification through Campbell diagram 
Speed is categorized in to three type's low idle, high idle and rated rpm. Speed which comes under $800 \mathrm{rpm}$ is considered as low idle rpm. Rated at $2000 \mathrm{rpm}$ and high idle up to $2150 \mathrm{rpm}$. From Fig 13 it can be observed that 101.81 $\mathrm{Hz}$ Muffler mode interferes with the 3rd order engine excitation frequency at $2000 \mathrm{rpm}$. This point can be considered as resonance point. But there is no significant peak in the excitation frequency. Peak frequency is obtained from engine acceleration data which is converted from time domain to frequency domain through Fast Fourier transformation. At this point there is no major crest in all the direction right from bottom left to top right both fore-aft and side by side directions.

\section{FREQUENCY RESPONSE ANALYSIS}

Any sustained cyclic load will produce a sustained cyclic response (a frequency response) in a structural system. Modal analysis helps to determine the modes of vibrations and the frequencies at which those modes are triggered. Response analysis will provide the real deformation that an excitation of one of those modes will actually cause.

Frequency response analysis gives you the ability to predict the sustained dynamic behavior of your structures, thus enabling you to verify whether existing design will sustain resonance, fatigue, and other detrimental effects of forced vibrations.

\section{Acceptance Criteria}

Bracket should be designed for infinite life with stress ranges not exceeds $31 \mathrm{MPa}$ or 150 micro strain range for welded fabrications or locations. The limit is set weld acceptance criteria.
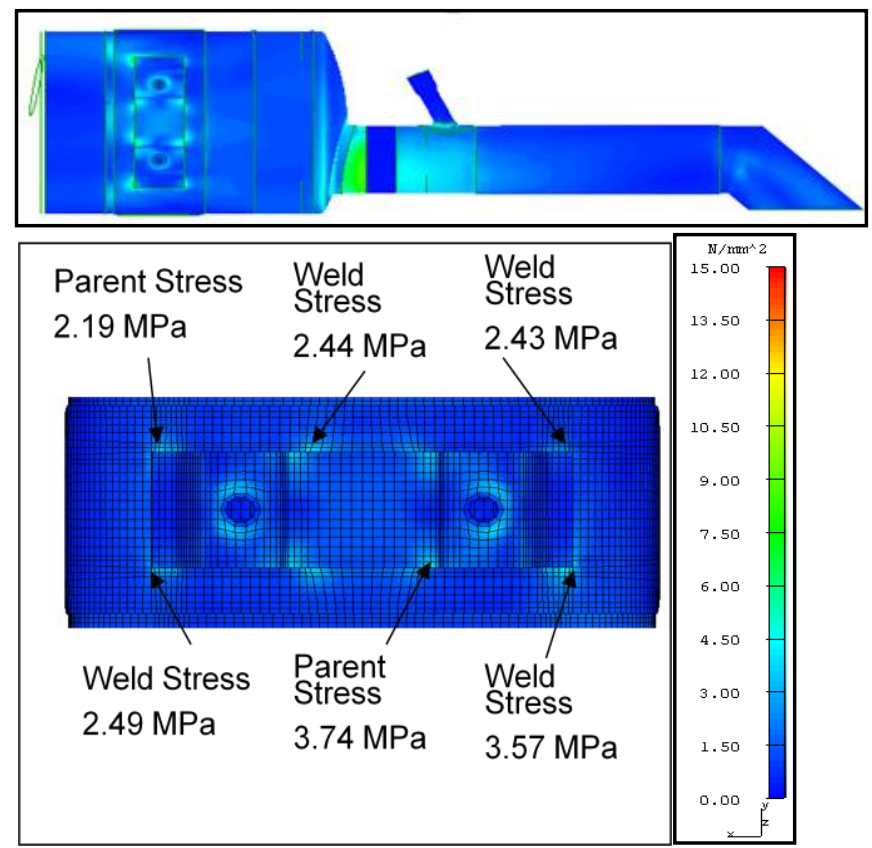

Fig -14: Von mises peak stress

Parent stress location is considered as other than the weld region.
Table -3: Strain at adjacent components

\begin{tabular}{|l|l|}
\hline Location & Strain (Micro Strain range) \\
\hline Muffler - Inlet collar & 182 \\
\hline Muffler - Outlet collar & 68 \\
\hline Muffler -Inlet & 61 \\
\hline Muffler - Outlet & 102 \\
\hline Muffler - W bracket & 99 \\
\hline
\end{tabular}

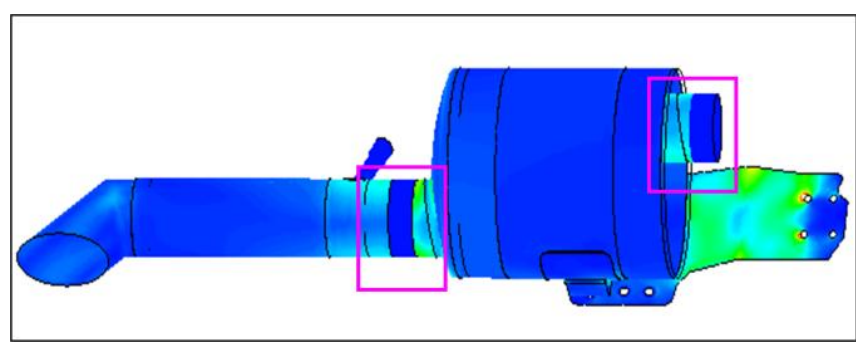

Fig -15: Weld stress location

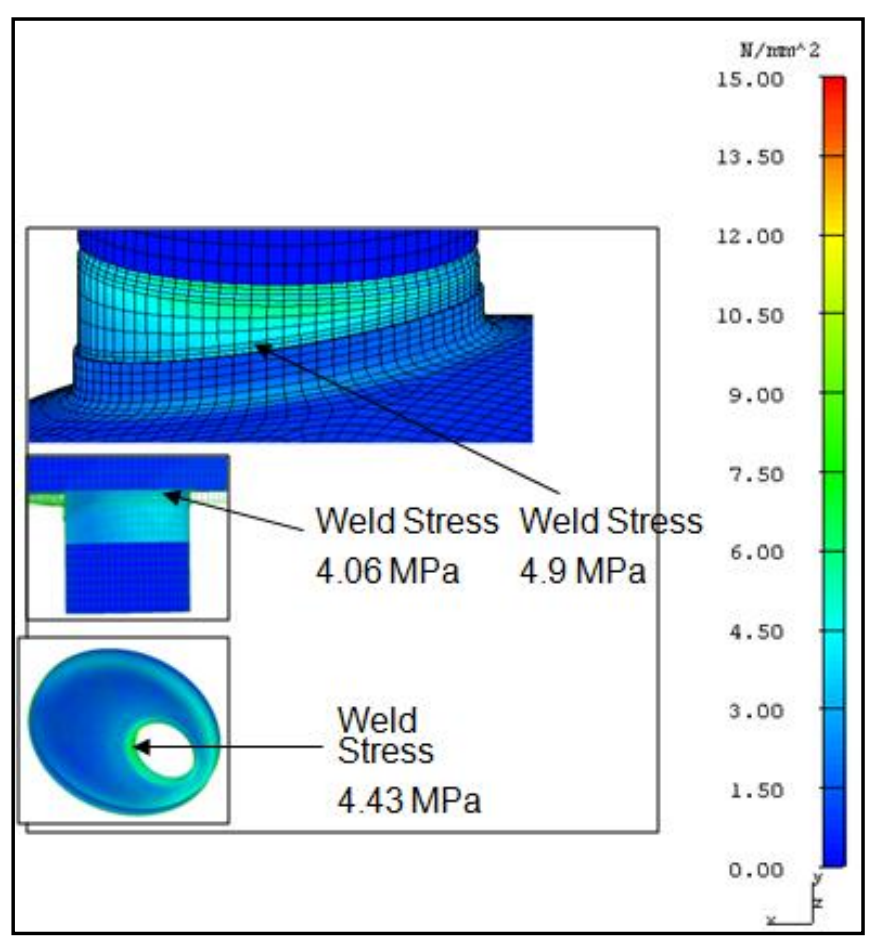

Fig -16: weld stress at collar location

Strain range at weld location

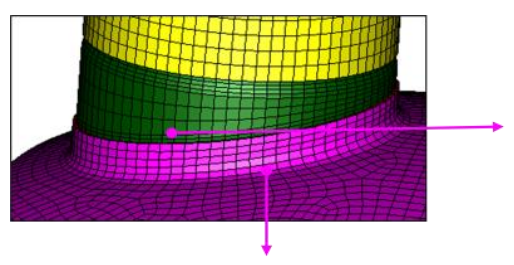

Muffler - Outlet weld location 102 micro strain range

Muffler - Outlet collar location 68 micro strain range

Fig -17: Strain range at muffler 


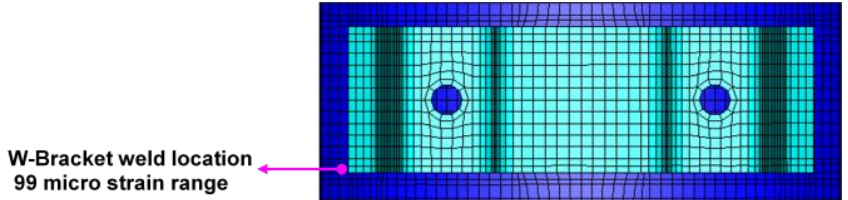

Fig -18: Strain at $\mathrm{W}$ - Bracket

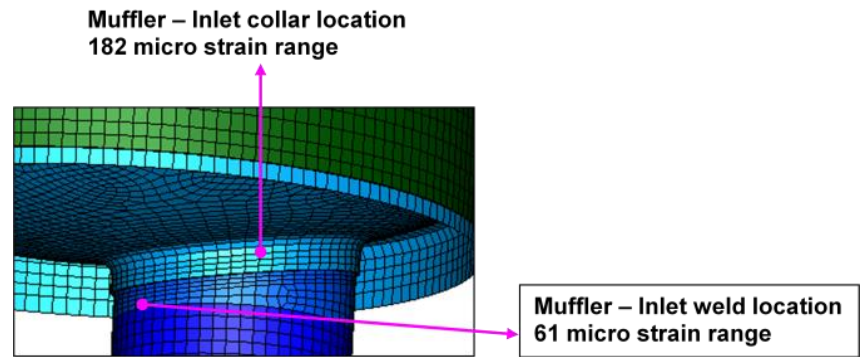

Fig -19: Strain at inlet collar location

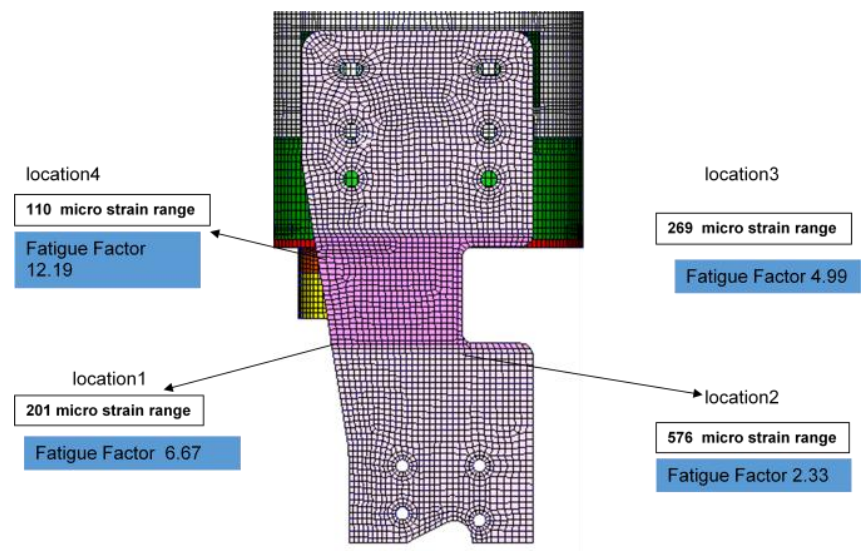

Fig -20: Strain and fatigue factor for mounting bracket

Table -4: Micro strain range for bracket

\begin{tabular}{|l|l|}
\hline Location & $\begin{array}{l}\text { Strain (Micro } \\
\text { Strain range) }\end{array}$ \\
\hline 1 & 201 \\
\hline 2 & 576 \\
\hline 3 & 269 \\
\hline 4 & 110 \\
\hline
\end{tabular}

\section{Fatigue Factor Calculation}

\section{FF $=$ Endurance Limit *(1-SigmaM/UTS $) /$ Sigma A}

UTS: Ultimate Tensile strength

Sigma mean $\mathrm{M}=$ Mean stress $=0$

Sigma A = Alternating stress $=116 \mathrm{MPa}$

Table -5: Fatigue factor for bracket

\begin{tabular}{|l|l|}
\hline Location & $\begin{array}{l}\text { Fatigue } \\
\text { Factor }\end{array}$ \\
\hline 1 & 6.67 \\
\hline 2 & 2.33 \\
\hline 3 & 4.99 \\
\hline 4 & 12.19 \\
\hline
\end{tabular}

\section{CONCLUSION}

Frequency response analysis of exhaust system assembly helps in many ways and methodology helps to take verdict on different components like excitation, vibration response and structure. Stress results of different mounting components helps in design iteration of individual components of mechanism. Acceleration plots will helps to indentify how much $\mathrm{G}$ force is coming on components with respect to $\mathrm{rpm}$.

Form outputs of frequency response analysis, the weld stress are in within the limits and strain range at weld location are within 150 micro strain ranges.

Micro strain range for all the critical locations on bracket are within permissible limit. The Fatigue Factor for the Parent material of support bracket is greater than 2, which is within the acceptable limit. Strain ranges at the hotspots locations are below the acceptance criteria except at the inlet collar location, to increase the fatigue factor for inlet collar location the radius of cut of the support bracket can be increased.

Hence, mounting system can withstand the dynamic loads generated through random vibrations.

\section{ACKNOWLEDGEMENT}

I would like to thank each one who helped me for better understanding of exhaust mounting concepts and providing sufficient information and their kind support to enhance my skills.

\section{REFERENCES}

[1]. To Study the Dynamic Behaviour of Engine Assembly by Using Altair OptiStruct, Amit Joshi,

[2]. A study of vibration isolation engine mount system, Ruiping wang, Concordia university, March 2005

[3]. Analyzing random vibration fatigue, Santhosh M Kumar, Ansys, India

[4]. Modal Analysis and Harmonic Response Analysis of a Crankshaft,Dr C. M Ramesha, Abhijith K G , Abhinav Singh, Abhishek Raj, Chetan S Naik, IJETAE, Volume 5 Issue 6, June 2015

[5]. A study of vibration isolation engine mount system, Ruiping wang, Concordia university, March 2005

[6]. Vibration Analysis of An Engine Mount, Fernando M. D. Damos, Departamento de Engenharia Mecânica Instituto Superior Técnico, Portugal 